\title{
Perancangan E-Commerce Berbasis Web pada PT. Touch Technology Indonesia
}

\author{
Ahmad Saubani $^{1}$, Esron Rikardo Nainggolan ${ }^{2}$, Siti Nur Khasanah $^{3}$ \\ 1,2,3 Teknik Informatika, STMIK Nusa Mandiri, Jakarta, Indonesia \\ e-mail: ${ }^{1}$ myname@ahmadsaubani.com, ${ }^{2}$ esron.ekg@ nusamandiri.ac.id, ${ }^{3}$ siti.skx@ @usamandiri.ac.id
}

\begin{abstract}
Sales in this case in the form of product sales is one of the important activities for the development of the company and is a very important aspect for the company. Problems a rising in the company regarding the promotion and sales, because it still uses manually, visit home for promotion and provide brochures on the road side, System design used with a waterfall methode, while the data collection techniques use research methods with observation, interviews, and library studies. And database application development tools use MySQL and PHP programming language by using Laravel framework. The purpose of this research is to design a sales system evenly and ease of transaction customers without having to come to physical stores directly. The result of this research is to provide an alternative sales and promotion. It is application created can create increase in company sales.
\end{abstract}

Keywords: Sales, E-Commerce, Sales Promotion

\begin{abstract}
Abstrak
Penjualan dalam hal ini dalam bentuk penjualan produk merupakan salah satu kegiatan penting untuk pengembangan perusahaan dan merupakan aspek yang sangat penting bagi perusahaan. Permasalahan yang timbul di perusahaan mengenai promosi dan penjualan, Karena masih menggunakan secara manual, berkunjung ke rumah untuk promosi dan memberikan brosur di sisi jalan, Desain sistem digunakan dengan metode waterfall, sedangkan teknik pengumpulan data menggunakan metode penelitian dengan observasi, wawancara, dan studi perpustakaan. Dan alat pengembangan aplikasi database menggunakan bahasa pemrograman MySQL dan PHP dengan menggunakan framework Laravel. Tujuan dari penelitian ini adalah merancang sistem penjualan secara merata dan kemudahan transaksi pelanggan tanpa harus datang langsung ke toko fisik. Hasil dari penelitian ini adalah memberikan alternatif penjualan dan promosi. Ini adalah aplikasi yang dibuat dapat menciptakan peningkatan penjualan perusahaan.
\end{abstract}

Keywords: Penjualan, E-Commerce, Promosi

\section{Pendahuluan}

Pada era komputerisasi ini kebutuhan manusia akan informasi memacu pesatnya perkembangan teknologi di bidang informasi dan teknologi. Teknologi yang semakin meningkat didukung dengan sarana dan prasarana yang memadai, membuktikan bahwa kini informasi telah menjadi kebutuhan pokok dalam kehidupan manusia.

PT. Touch Technology Indonesia merupakan perusahaan Start up yang menjual berbagai macam aksesoris handphone kelas premium di Indonesia. Sistem penjualan produk aksesoris pada PT. Touch Technology Indonesia masih menggunakan cara manual seperti mengenalkan produk kepada konsumen pintu ke pintu dan mempromosikan produk di pinggir jalan, sehingga pemilik memerlukan aplikasi $E$ Commerce berbasis web untuk memperkenalkan perusahaan, produk dan penjualan produk secara online.

kepercayaan konsumen dalam melakukan online shopping merupakan suatu kendala yang sulit dikendalikan karena berhubungan dengan sikap dan prilaku konsumen sehubung dengan online shopping agar pelaku usaha E-Commerce dapat memanfaatkan potensi yang ada di Indonesia. Kualitas dari website E-Commerce dapat berpengaruh pada banyaknya pelanggan yang memutuskan untuk berbelanja online pada $E$ Commerce tersebut (Agustina, 2016).

Para remaja sampai ibu rumah tangga, juga kini mudah mengakses internet dari rumah dan di mana saja untuk berbagai keperluan, mulai dari 
browsing mencari informasi, berbelanja online, atau memang memiliki bisnis online (Sudarsono, 2014).

Perilaku pada konsumen E-Commerce memang sedikit berbeda dengan perilaku konsumen tradisional. Bagi konsumen online, melakukan transaksi dengan pemasar online akan mempertimbangkan ketidakpastian dan resiko jika dibandingkan dengan transaksi jual beli secara tradisional. Ketika pelanggan melakukan pembelian dari website pemasar yang tidak dikenal, mereka tidak dapat mengetahui kualitas barang dan jasa yang ditawarkan Menurut (Fauziah \& Wulandari, 2018).

\section{Metode Penelitian}

Teknik pengumpulan data yang digunakan penulis meliputi metode observasi, metode wawancara dan metode studi pustaka, selain itu penulis juga menggunakan metode pengembangan sistem yaitu metode waterfall.

Tahapan metode waterfall yang penulis lakukan antara lain (Rosa \& Shalahuddin, 2014):

A. Analisa kebutuhan sistem

Proses pengumpulan kebutuhan secara insentif untuk menspesifikasikan kebutuhan untuk pengenalan tentang perusahaan, sistem penjualan produk secara luas, dan dapat dengan mudah diakses oleh masyarakat baik menggunakan desktop maupun mobile.

B. Desain

Dalam tahap ini penulis menggunakan database MySQL dan desain sistem dibuat menggunakan UML (Use Case Diagram, Activity Diagram, Component Diagram, dan Deployment Diagram). Program ini berisi sub sistem mulai dari pengolahan data penjualan PT. Touch Technology Indonesia.

C. Code Generation

Penulis menggunakan bahasa pemrograman PHP, HTML5 beserta Bootstrap untuk tampilan yang responsive agar dapat digunakan baik di desktop maupun mobile dengan menggunakan framework Laravel dan database MySQL.
D. Testing

Tahap ini dilakukan pengujian yang sudah dibuat, pengujian dilakukan dengan blackbox, yaitu menemukan kesalahan serta memastikan output yang dihasilkan sesuai dengan yang diinginkan.

\section{Pembahasan}

Pada pembahasan ini penulis membagi dua bagian yaitu:

A. Analisa sistem berjalan

Pada tahap ini akan digambarkan dokumentasi alur kerja sistem yang sedang berjalan menggunakan activity diagram.

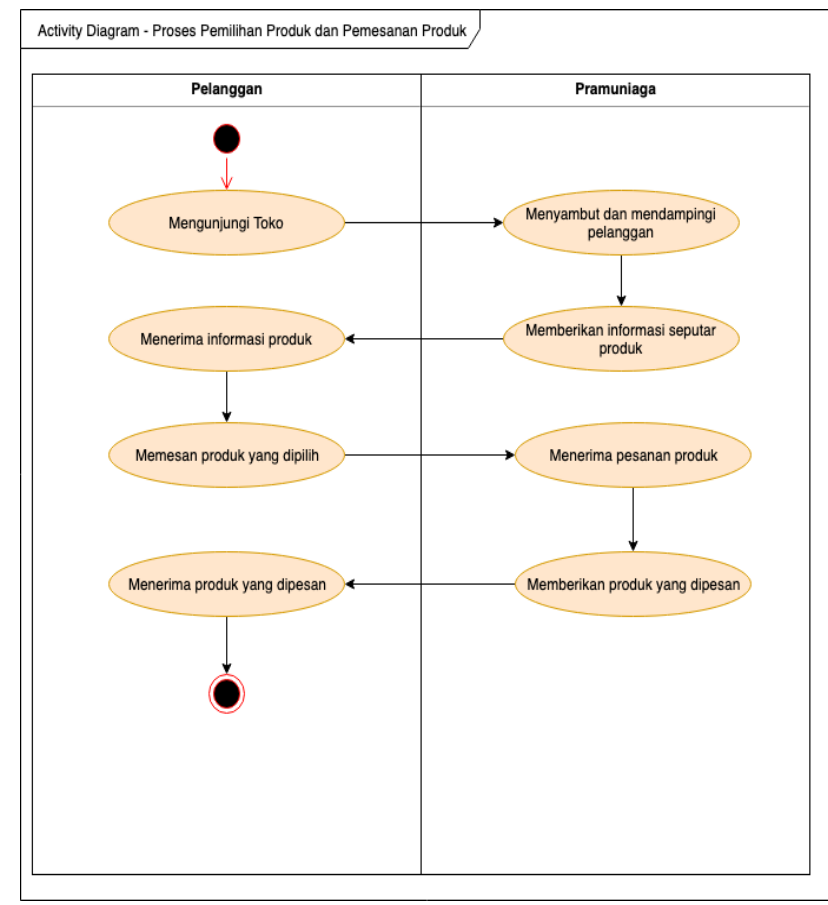

Gambar 1 Activity Diagram Proses pemilihan dan pemesanan produk

Pada Activity Diagram ini dapat dilihat interaksi antara pelanggan dengan pramuniaga pada saat proses pemilihan dan pemesanan produk. 


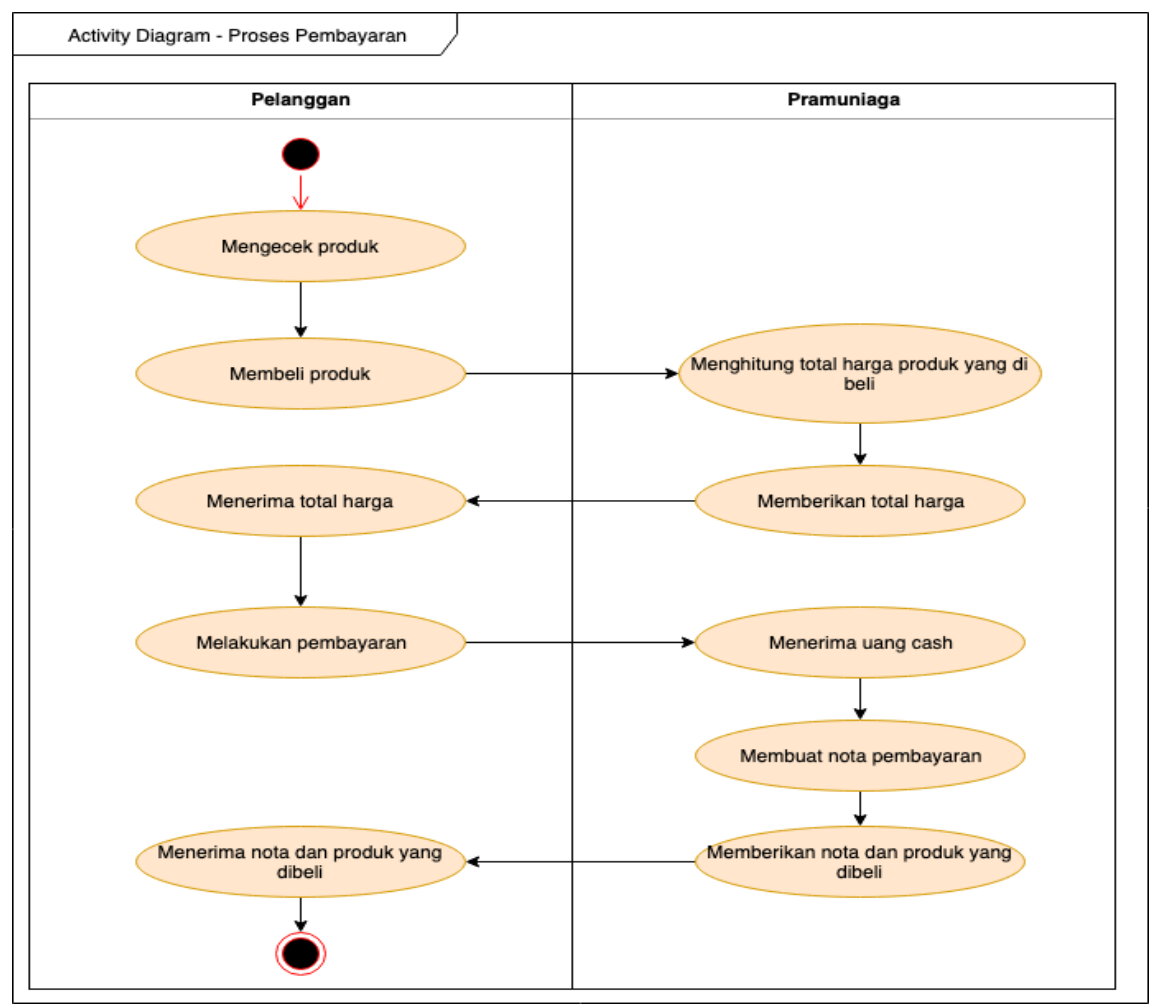

Gambar 2 Activity Diagram Proses Pembayaran

Pada Activity Diagram ini dapat dilihat interaksi antara pelanggan dengan pramuniaga pada saat proses pembayaran.

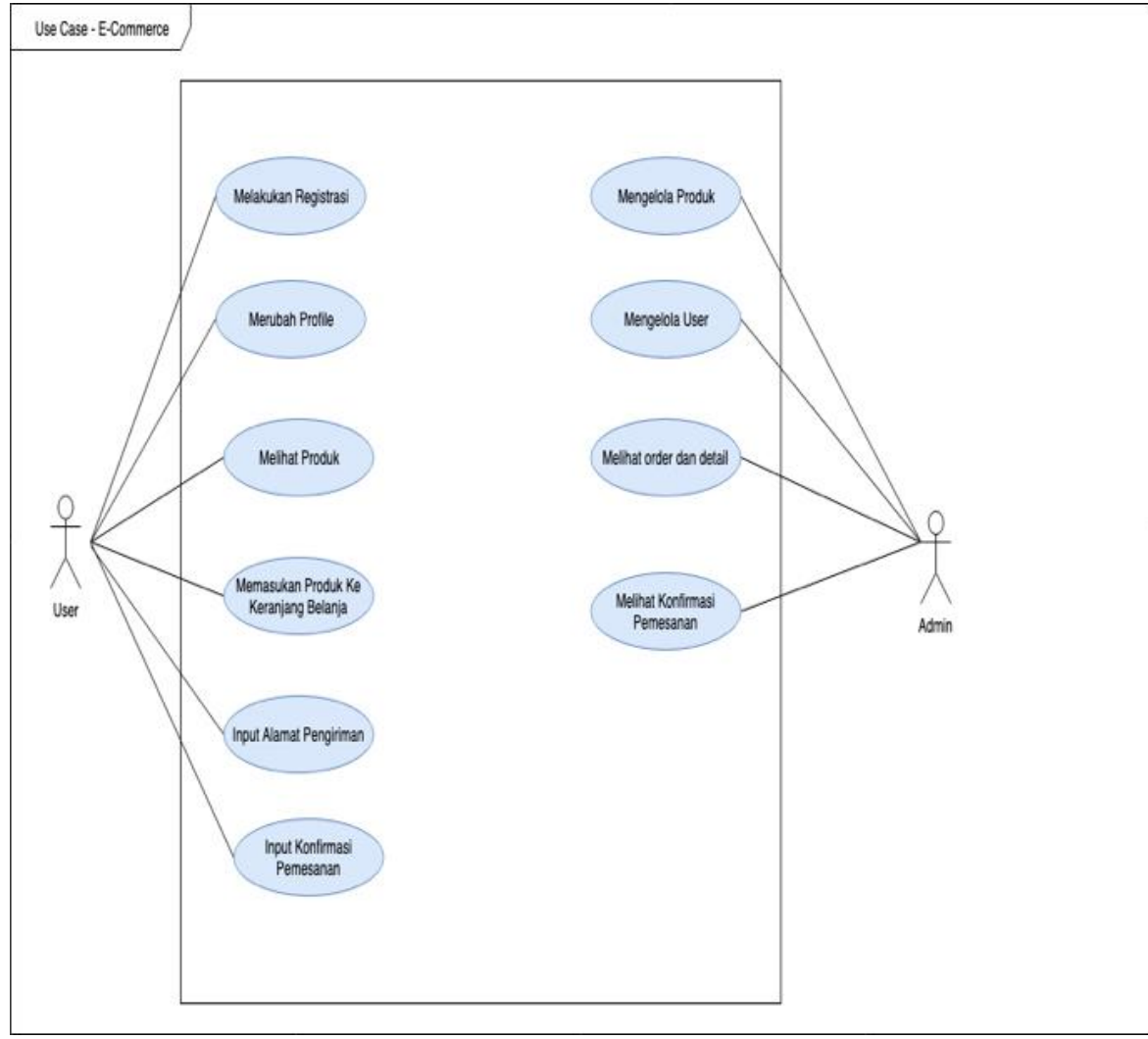

Gambar 3 Use Case Diagram 
B. Rancangan sistem usulan dan program usulan, sebagai berikut:

a. Halaman User

A1. User dapat mengubah profile

A2. User dapat memilih produk

A3. User dapat memasukkan produk dan banyaknya order ke keranjang belanja

A4. User dapat memasukkan alamat pengiriman

A5. User dapat melakukan konfirmasi pemesanan

b. Halaman Administrator
B1. Admin dapat mengelola produk

B2. Admin dapat mengelola user

B3. Admin dapat melihat daftar pesanan

B4. Admin dapat melihat rincian pesanan

B5. Admin dapat melihat konfirmasi pesanan

Dalam database desain akan digambarkan dalam suatu Entity Relationship Diagram (ERD), serta memaparkan penjelasan dari Entity Relationship Diagram (ERD) tersebut.

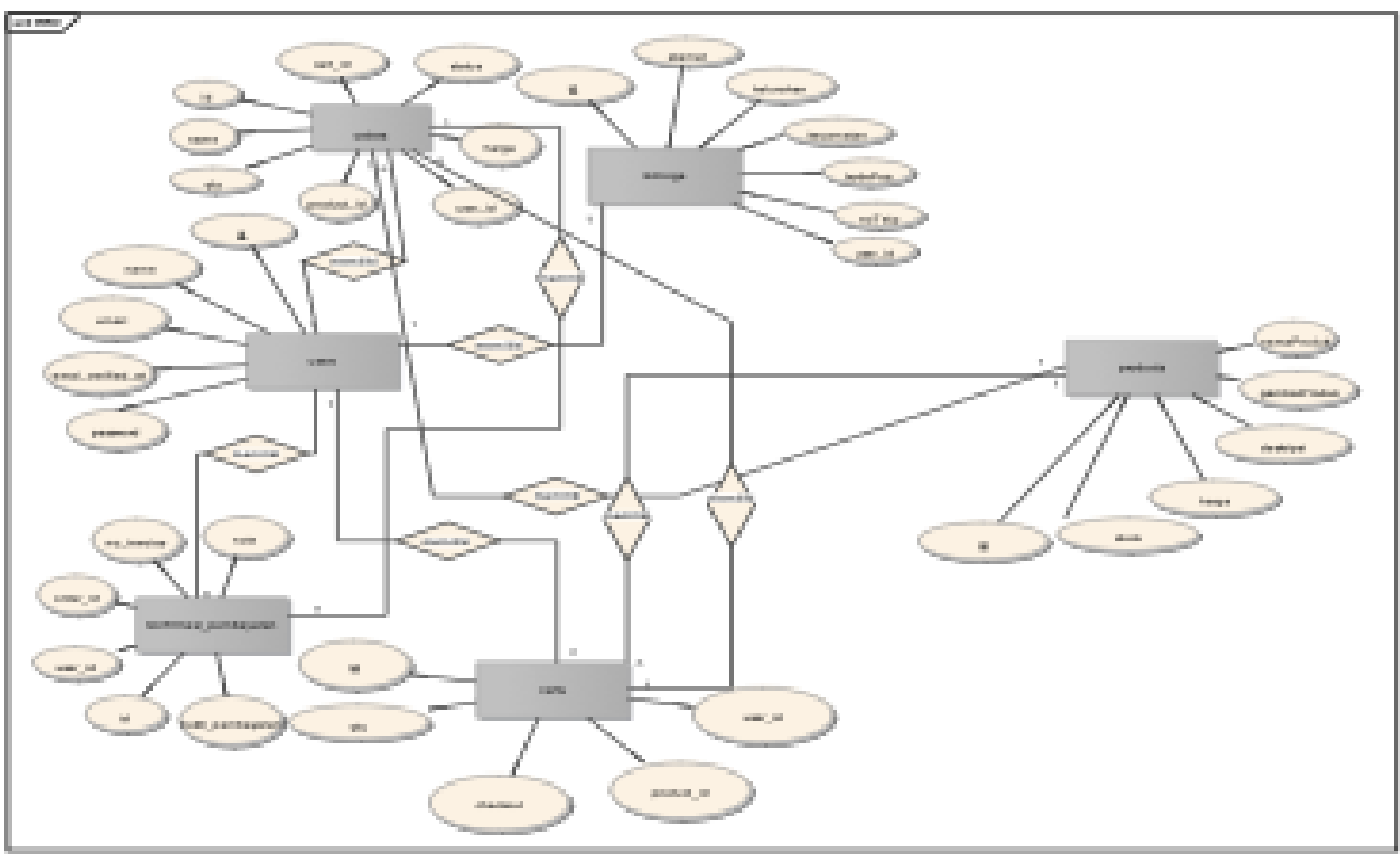

Gambar 4 Entity Relationship Diagram

1. Tabel User

Tabel user ini berisikan data untuk menampung semua user yang terdaftar di dalam website, dan Panjang record dihitung dari setiap Field Panjang record yang tersedia di tabel user.

$\begin{array}{ll}\text { Nama File } & : \text { Users } \\ \text { Akronim } & : \text { users.myd } \\ \text { Tipe File } & : \text { File Master } \\ \text { Akses File } & : \text { Random } \\ \text { Panjang Record } & : 146 \text { Bytes } \\ \text { Kunci File } & : \text { id }\end{array}$

Tabel 1 Users

\begin{tabular}{|c|c|c|c|c|c|}
\hline No & Element Data & Akronim & Tipe & Panjang Record & Keterangan \\
\hline 1 & id & Kode User & int & 11 & Primary Key \\
\hline 2 & name & Nama User & varchar & 45 & - \\
\hline 3 & email & Email User & varchar & 45 & - \\
\hline 4 & email_verified_at & Email User Verifikasi & datetime & - & - \\
\hline 5 & password & Password User & varchar & 45 & - \\
\hline
\end{tabular}


2. Tabel Billing

Tabel billings ini berisikan data untuk menampung semua alamat user yang terdaftar di dalam website, dan Panjang record dihitung dari setiap Field Panjang record yang tersedia di tabel billings.
Nama File

Akronim

Tipe File

Akses File

Panjang Record

Kunci File
: Billings

: billings.myd

: File Transaction

: Random

: 247 Bytes

: id

Tabel 2 Billings

\begin{tabular}{|c|c|c|c|c|c|}
\hline No & Element Data & Akronim & Tipe & Panjang & Keterangan \\
\hline 1 & id & Kode Billing & int & 11 & Primary Key \\
\hline 2 & alamat & Alamat Billing & varchar & 45 & - \\
\hline 3 & kelurahan & Kelurahan Billing & varchar & 45 & - \\
\hline 4 & kecamatan & Kecamatan Billing & varchar & 45 & - \\
\hline 5 & kota & Kota Billing & varchar & 45 & - \\
\hline 6 & noTelp & No Telp Billing & varchar & 45 & - \\
\hline 7 & user_id & User_id Billing & int & 11 & Foreign Key \\
\hline
\end{tabular}

3. Tabel Product

Tabel Product ini berisikan data untuk menampung semua product yang terdaftar di dalam website, dan Panjang record dihitung dari setiap Field Panjang record yang tersedia di tabel product.

$\begin{array}{ll}\text { Nama File } & : \text { Products } \\ \text { Akronim } & : \text { products.myd } \\ \text { Tipe File } & : \text { File Master } \\ \text { Akses File } & : \text { Random } \\ \text { Panjang Record } & : 112 \text { Bytes } \\ \text { Kunci File } & : \text { id }\end{array}$

Tabel 3 Products

\begin{tabular}{|c|c|c|c|c|c|}
\hline No & Element Data & Akronim & Tipe & Panjang & Keterangan \\
\hline 1 & id & Kode Product & int & 11 & Primary Key \\
\hline 2 & namaProduk & Nama Product & varchar & 45 & - \\
\hline 3 & gambarProduk & Gambar Product & longText & - & - \\
\hline 4 & deskripsi & Deskripsi Product & longText & - & - \\
\hline 5 & harga & Harga Product & varchar & 45 & - \\
\hline 6 & stock & Stock Product & int & 11 & - \\
\hline
\end{tabular}

4. Tabel Cart

Tabel Cart ini berisikan data untuk menampung semua produk yang telah di masukkan ke keranjang belanja yang dilakukan user, dan Panjang record dihitung dari setiap Field Panjang record yang tersedia di tabel cart.
Akronim

Tipe File

Akses File

Panjang Record

Kunci File
: carts.myd

: File Transaction

: Random

: 44 Bytes

: id

Nama File $\quad$ : Carts

Tabel 4 Carts

\begin{tabular}{|l|c|c|c|c|c|}
\hline No & Element Data & Akronim & Tipe & Panjang & Keterangan \\
\hline 1 & id & Kode Cart & int & 11 & Primary Key \\
\hline 2 & qty & Qty Cart & int & 11 & - \\
\hline 3 & checkout & Checkout Cart & tiny int & - & - \\
\hline 4 & user_id & User_id Cart & int & 11 & Foreign Key \\
\hline 5 & product_id & Product_id Cart & int & 11 & Foreign Key \\
\hline
\end{tabular}


5. Tabel Order

Tabel Order ini berisikan data untuk menampung semua produk yang telah di pesan yang dilakukan oleh user, dan Panjang record dihitung dari setiap Field Panjang record yang tersedia di tabel order.

$\begin{array}{ll}\text { Nama File } & \text { : Orders } \\ \text { Akronim } & \text { : orders.myd } \\ \text { Tipe File } & \text { : File Transaction } \\ \text { Akses File } & : \text { Random } \\ \text { Panjang Record } & : \text { 190 Bytes } \\ \text { Kunci File } & : \text { id }\end{array}$

Tabel 5 Orders

\begin{tabular}{|c|c|c|c|c|c|}
\hline No & Element Data & Akronim & Tipe & Panjang & Keterangan \\
\hline 1 & id & Kode Order & int & 11 & Primary Key \\
\hline 2 & name & Name Order & varchar & 45 & - \\
\hline 3 & nameProduk & Name Produk Order & varchar & 45 & - \\
\hline 4 & qty & Qty Order & int & 11 & - \\
\hline 5 & harga & Harga Order & varchar & 45 & - \\
\hline 6 & status & Status Order & tiny int & - & - \\
\hline 7 & user_id & User_id Order & int & 11 & Foreign Key \\
\hline 8 & cart_id & Cart_id Order & int & 11 & Foreign Key \\
\hline 9 & product_id & Product_id Order & int & 11 & Foreign Key \\
\hline
\end{tabular}

6. Tabel Konfirmasi Pemesanan

Tabel konfirmasi pemesanan ini berisikan data untuk menampung semua konfirmasi yang telah dilakukan oleh user untuk konfirmasi pemesanan, dan Panjang record dihitung dari setiap Field Panjang record yang tersedia di tabel konfirmasi

Nama File Akronim

Tipe File

Akses File

Panjang Record

Kunci File
: konfirmasi_pemesanan : konfirmasi_pemesanan.myd

: File Transaction

: Random

: 146 Bytes

: id pemesanan.

Tabel 6 Konfirmasi Pemesanan

\begin{tabular}{|c|c|c|c|c|c|}
\hline No & Element Data & Akronim & Tipe & Panjang & Keterangan \\
\hline 1 & id & Kode Pemesanan & int & 11 & Primary Key \\
\hline 2 & user_id & User_id Pemesanan & int & 11 & Foreign Key \\
\hline 3 & order_id & Order_id Pemesanan & int & 11 & Foreign Key \\
\hline 4 & no_invoice & No Invoice Pemesanan & varchar & 45 & - \\
\hline 5 & bukti_pembayaran & Bukti Pembayaran Pemesanan & longText & - & - \\
\hline
\end{tabular}

Tampilan user interface dari pembuatan web e-commerce adalah:

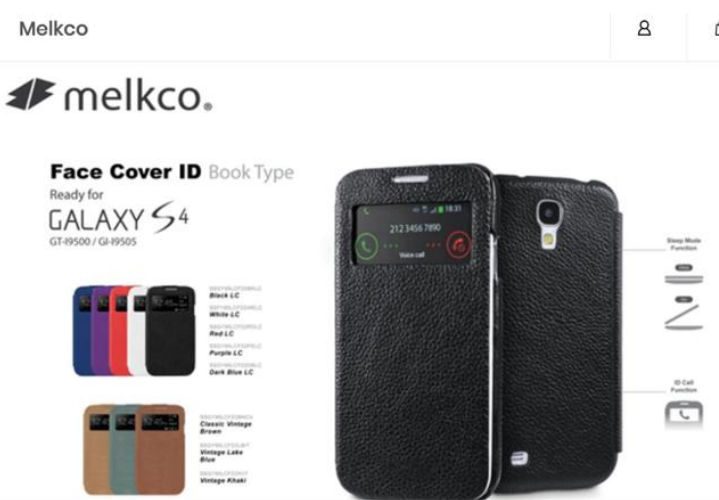

Gambar 5 Tampilan awal

Ini merupakan tampilan awal ketika user mengakses web melkco. Pada halaman ini juga user dapat melihat semua product yang dijual oleh melkco di toko offline nya.

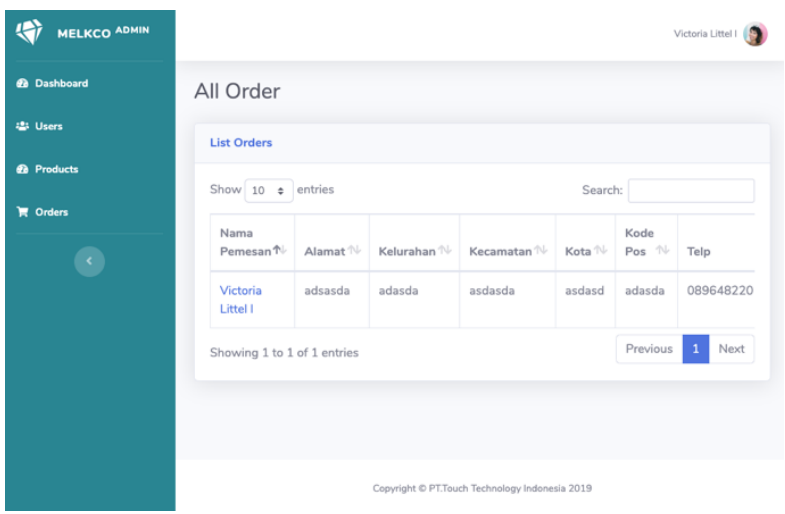

Gambar 6 Tampilan List Pesanan

Pada halaman ini merupakan halaman admin yang dapat melihat pesanan user. Dan di halaman ini juga admin dapat melihat data seperti alamat 
pengiriman, nama penerima dan nomor telepon pembeli.

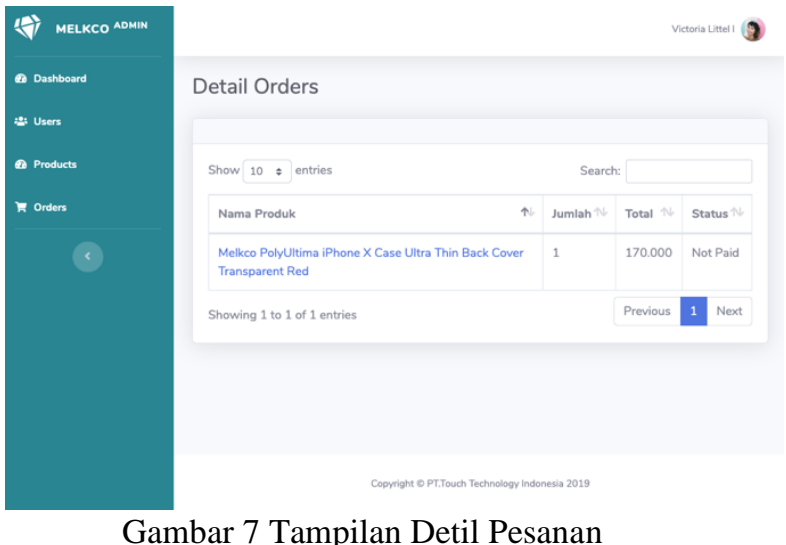

Pada halaman ini admin dapat melihat detil pesanan yang di pesan oleh user, data yang akan ditampilkan yaitu seperti nama produk yang dipesan, jumlah produk yang dipesan, total harga dan status pembayaran user.

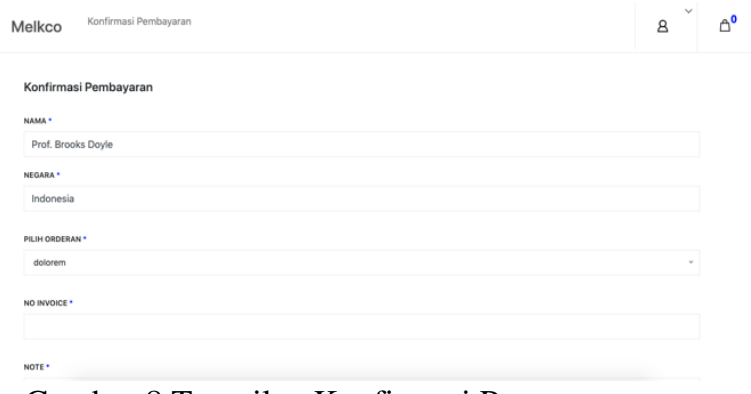

Gambar 8 Tampilan Konfirmasi Pemesanan

Pada halaman ini user dapat konfirmasi setelah melakukan pembayaran, dan tentu user harus unggah bukti transfer.

\section{Kesimpulan}

Dari seluruh pembahasan, maka penulis mengambil beberapa kesimpulan sebagai berikut:

A. Dengan adanya web e-commerce yang telah dibuat ini, penjualan dapat lebih meluas secara merata disetiap daerah sehingga membantu dalam melakukan penjualan baik secara offline maupun secara online.

B. Penyimpanan data dalam database memudahkan dalam penyimpanan, pencarian dan pemeliharaan data, sehingga kita tidak perlu menyimpan data dalam media kertas yang mudah hilang dan rusak seperti pada sistem manual dengan menggunakan media kertas.

C. Sistem komputerisasi dapat meminimalisir kesalahan yang mungkin terjadi seperti kesalahan input, hilangnya media kertas nota pembayaran dan banyak lagi.

\section{Saran-Saran}

Saran yang penulis dapat sampaikan adalah:

A. Sistem yang dirancang hanya sebatas penjualan produk saja, diharapkan pada masa yang akan datang dapat diperbaharui secara mendalam agar dapat dilakukan pengolahan data lainnya dalam satu aplikasi yang terkomputerisasi.

B. Diharapkan pada masa yang akan datang akan ada pengembangan baik berupa penambahan fitur aplikasi yang dibutuhkan oleh perusahaan.

C. Diharapkan ke depannya, adanya sistem Payment Gateway seperti Midtrans, Xendit dan lain-lain, sehingga memudahkan customer membayar tagihan ke berbagai nomor rekening pilihan yang tersedia.

\section{Referensi}

Agustina, N. (2016). Kualitas Layanan Website ECommerce Lazada.co.id Menggunakan Teknik Pengukuran WebQual. Information System for Educator And Professional Vol.1, No. 1, Desember 2016, 42-54 E-ISSN: 2548-3587, 1(1), 42-54.

Ahmia, M., \& Belbachir, H. (2018). p, q-Analogue of a linear transformation preserving log-convexity. Indian Journal of Pure and Applied Mathematics, 49(3), 549-557. https://doi.org/10.1007/s13226018-0284-5

Darwati, N. A. (2017). Perancangan Web E-Commerce Pada Penjualan Jam Tangan. Jurnal Informatika, III(1), 74-79. https://doi.org/10.31294/JTK.V3I1.1345

Endang, R. (2016). Sistem Informasi Simpanan dan Pembiayaan Pada Baitul Maal wat Tamwil (BMT) Al-Multazam Kabupaten Tegal. Evolusi, 3(2), 2432. Retrieved from http://lppm3.bsi.ac.id/jurnal/index.php/evo/article /view/237

Fauziah, D., \& Wulandari, D. (2018). Pengukuran Kualitas Layanan Bukalapak.com Terhadap Kepuasan Konsumen dengan Metode Webqual 4.0. Jurnal Ilmu Pengetahuan Dan Teknologi Komputer, 3(2), 173-180. 